\title{
Performance Measurement Analysis Of PT.Pijar Sukma Using Performance Prism, Analytical Hierarchy Process (AHP), And Objective Matrix (OMAX) Methods
}

\author{
Afifah $^{1}$, Akhmad Syakhroni $^{2}$, Nuzulia Khoiriyah ${ }^{3}$ \\ 1 Universitas Islam Sultan Agung \\ 2 Universitas Islam Sultan Agung \\ 3 Universitas Islam Sultan Agung
}

\begin{abstract}
PT. Pijar Sukma is a furniture industry company, located in Jepara, Central Java. PT. Pijar Sukma is having problems that customer order requests cannot be fulfilled according to production targets. So companies need tools that can measure performance. This research uses the performance prism method which involves stakeholders so that they can form the sides of the prism, namely satisfaction, contribution, strategy, process, and capability. From these methods used to compile key performance indicators (KPIs), 30 KPIs were produced based on satisfaction and contributions in the design that had been prepared, there were 10 strategic KPIs, 10 process KPIs, and 10 capability KPIs that were weighted through the analytical hierarchy process $(A H P)$ method, then scored using the analytical hierarchy process (AHP) method. OMAX to provide an actual value with a score of 1-10 on each KPI and the traffic light system as a color assignment, namely green means very good / the target is maximally appropriate, yellow is quite good/ the target has not reached the maximum, and red means bad / the target has not been maximized. The results of the processing and calculation show that the company's performance index value of 2.836 is categorized as red with an actual value of 3.00, meaning the company has achieved the performance measurement plan but has not reached the set target so that the company can maintain good performance and make changes to poor performance by improving performance in red.
\end{abstract}

Keywords: Key Performance Indicators (KPI); Performance Prism; Analytical Hierarchy Process (AHP); Objective Matrix (OMAX); Traffic Light System.

corresponding email : afifah0000@student.unissula.ac.id

This is an open access article under the $\underline{C C B Y}$ license

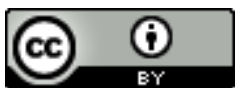

\section{INTRODUCTION}

Di era perkembangan teknologi yang begitu cepat berkembang dan semakin canggih. Dengan adanya perkembangan teknologi, mengakibat persaingan bisnis usaha semakin ketat. Dibutuhkan sistem pengukuran kinerja yang bertujuan untuk meningkatkan kinerja perusahaaan. Pengukuran kinerja mampu mengukur kinerja secara lebih akurat dan kompetitif, dilihat dari stakeholder, aspek finansial, visi misi organisasi dan lain-lain merupakan indikator kinerja. Persaingan bisnis khususnya di bidang furniture adalah PT. Piajr Sukma di Jepara, Jawa Tengah. Persaingan bisnis yang terjadi tidak dapat dihindari, agar mampu bersaing PT. Pijar Sukma meningkatkan aspek finansial dan non finansial. PT Pijar Sukma melakukan proses produksi 5 hari yaitu hari senin sampai dengan jumat. Terjadi peningkatkan jumlah produksi mengakibatkan pengiriman produk mengalami keterlambatan dan tidak bisa menyelesaikan tepat waktu.

Tabel 1 Data Produksi Barang PT Pijar Sukma

\begin{tabular}{ccccc}
\hline Tahun & Bulan & Target Produksi (Pcs) & Jumlah Produksi (Pcs) & Keterangan \\
\hline \multirow{2}{*}{2020} & Desember & 3.500 & 3.200 & Tidak Tercapai \\
\cline { 2 - 5 } 2021 & Januari & 2.833 & 2.833 & Tercapai \\
\cline { 2 - 5 } & Februari & 3.523 & 3.202 & Tidak Tercapai \\
\cline { 2 - 5 } & Maret & 3.801 & 3.500 & Tidak Tercapai \\
\hline
\end{tabular}


JAST : Journal of Applied Science and Technology

Volume. 02 Number. 01, January 2022

ISSN : 2775-4022

http://jurnal.unissula.ac.id/index.php/JAST

\begin{tabular}{cccc}
\hline April & 3.000 & 3.000 & Tercapai \\
\hline Mei & 3.855 & 3.855 & Tercapai \\
\hline Juni & 3.544 & 3.500 & Tidak Tercapai \\
\hline Juli & 2.077 & 2.077 & Tercapai \\
\hline Agustus & 3.544 & 3.544 & Tercapai \\
\hline September & 3.988 & 3.790 & Tidak Tercapai \\
\hline Oktober & 3.750 & 3.750 & Tercapai \\
\hline November & 3.990 & 3.870 & Tidak Tercapai \\
\hline
\end{tabular}

Dari tabel diatas menunjukkan bahwa perusahaan masih belum bisa memenuhi permintaan pemesanan dari pelanggan dengan sesuai waktu yang targetkan. Waktu proses produksi selama 5 hari dengan banyak permintaan pemesanan mengakibatkan perusahaan harus menambah waktu produksi menjadi 7 hari dan menambah sift kerja. Kondisi ini jika dibiarkan terus menerus mengakibatkan penurunan kinerja yang berdampak hilangnya kepercayaan pelanggan dan menurunnya pendapatan perusahaan.

Kerusakan mesin terjadi setiap hari mengakibatkan penghambatan proses produksi jika perusahaan mengalami permintaan produksi secara meningkat dari pemesanan pelanggan. Kemudian dari pekerja masih bekerja kurang maksimal seperti tingkat Sumber Daya Manusia (SDM) rendah menjadikan sulit memahami konsep dari desain barang terbaru yang selalu berganti dari permintaan pelanggan, mengakibatkan proses produksi menjadi terlambat. Berdampak pemutusan hubungan kerja bagi pekerja yang kurang memiliki kinerja yang baik. PT. Pijar Sukma membutuhkan alat ukur kinerja yang dapat menggambarkan kinerja keseluruhan perusahaan dan menyelesaikan permasalahan di perusahaan. Pengukuran kinerja dapat memberikan perbaikan didalam perusahaan jika didapatkan hasil yang kurang memuaskan. Perusahaan dapat melakukan pengukuran kinerja dengan melibatkan stakeholder. Keberadaan stakeholder memiliki peran dalam kegiatan pengukuran kinerja sehingga dapat membantu dalam pencapaian kinerja perusahaan.

Oleh karena itu, perlu dilakukan analisis terkait pengukuran kinerja dengan melibatkan stakeholder perusahaan. Dengan mengetahui pengukuran kinerja dapat memberikan perbaikan didalam perusahaan jika didapatkan hasil yang kurang memuaskan. Keberadaan stakeholder memiliki peran dalam kegiatan pengukuran kinerja sehingga dapat membantu dalam pencapaian kinerja perusahaan.

\section{THEORETICAL BASIC}

\section{A. Pengukuran Kinerrja}

Pengukuran kinerja adalah tindakan pengukuran yang dilakukan terhadap berbagai aktivitas dalam rantai nilai yang ada pada perusahaan. Hasil pengukuran kemudian digunakan sebagai umpan balik dalam bentuk tindakan yang efektif dan efisien dan akan memberikan informasi tentang prestasi pelaksanaan suatu rencana dan titik dimana perusahaan memerlukan penyesuaian-penyesuaian atas aktivitas perencanaan dan pengendalian.

\section{B. Metode Performance Prism}

Performance Prism merupakan sebuah teori yang dikembangkan oleh Universitas Cranfield, kemudian pada tahun 2000 Neely, Adams, dan Kennerley mencoba memperkenalkannya sebagai sebuah metode pengukuran kinerja perusahaan. Metode ini mencoba memperbaiki kekurangan-kekurangan yang ada pada metode-metode sebelumnya seperti Balanced Scorecard dan Integradet Performance Measurement System (IPMS). Dengan kata lain pengukuran kinerja yang dilakukan tidak hanya terbatas pada beberapa stakeholder saja seperti yang dilakukan pada pengukuran kinerja pada metode terdahulu. Metode ini mengidentifikasi strategi, proses, dan kapabilitas yang dimiliki perusahaan serta mengidentifikasi kepuasaan dan kontribusi dari stakeholder.

Stakeholder itu sendiri dapat didefinisikan sebagai berikut. "Individu atau kelompok, baik di dalam maupun di luar perusahaan, yang mempunyai kepentingan terhadap hidup dan matinya perusahaan dan sekaligus dapat mempengaruhi kinerja organisasi” [8].

\section{Lima Perspektif pada Performance Prism}

Filosofi Performance Prism berasal dari sebuah bangun prisma yang memiliki lima sisi yaitu :

1. Stakeholder Satisfaction : siapa yang memiliki keinginan dan kebutuhan?

2. Strategi : strategi apa yang dibutuhkan untuk memberikan kepuasaan terhadap keinginan dan kebutuhan para stakeholder?

3. Proses : bagaimana proses untuk memenuhi kebutuhan yang ada dari strategi ?

4. Kapabilitas : kemampuan-kemampuan apa yang dibutuhkan untuk menjalankan proses yang ada?

5. Stakeholder Contribution : kontribusi apa yang dibutuhkan dan diinginkan dari para stakeholder.

D. Stakeholder dalam Performance Prism

Stakeholder mempunyai peran dalam pengukuran kinerja dengan metode performance prism adalah sebagai berikut [9]: 
1. Pemilik usaha

Perusahaan umumnya menerapkan usaha terbaiknya untuk mewujudkan kinerja sesuai pada kebutuhan dan keinginan pemilik usaha. Perusahaan juga harus mampu menyakinkan para pemilik agar dapat menanamkan modal sebagai dasar awal proses bisnis.

2. Konsumen

Konsumen merupakan unsur yang sangat penting bagi keberlangsungan sebuah perusahaan dan keberadaan konsumen menjadi tolak ukur untuk memenuhi target perusahaan.

3. Pekerja / tenaga kerja

Suatu perusahaan memerlukan kinerja yang kompoten dari pekerja/tenaga kerja untuk dapat menjalankan proses usahanya.

4. Supplier

Supplier sangat penting untuk mendukung proses perusahaan dari awal proses produksi. Dengan menjalin kerja sama yang baik antar keduanya, dapat memberikan keuntungan bagi kedua pihak.

5. Masyarakat sekitar perusahaan

Masyarakat sekitar perusahaan factor yang sering dikaitkan dengan pemerintah.

\section{E. Key Performance Indicator (KPI)}

KPI merupakan alat ukur yang digunakan untuk memperoleh manajemen ataupun para stakeholder untuk mengetahui tingkat kinerja dari perusahaa. KPI memeberikan strategi yang sangat jelas dan membantu untuk melakukan pengawasan dan perbakan pada kinerja perusahaan. Pemilihan KPI yang tidak tepat akan mengakibatkan pengukuran kinerja tidak efisien dan kontraproduktif. Berikut alur dalam penentapan KPI [10] :

1. Identifikasi KPI dan penentuan KPI terpilih

2. Pembobotan KPI dan pengesahan kontrak dengan pihak manajemen

3. Pengukuran dan pelaporan pencapaian KPI

4. Pengesahan pencapaian KPI, evaluasi dan umpan balik

\section{F. OMAX}

Metode OMAX relatif sederhana dan mudah dipahami, mudah dilaksanakan dan tak memerlukan keahlian khusus, atanya mudah diperoleh, dan lebih fleksibel, tergantung pada masalah yang dihadapi

\section{G. Traffic Light System}

Traffic Light System berhubungan erat dengan scoring system. Traffic Light System berfungsi sebagai tanda apakah score dari suatu indikator kinerja memerlukan suatu perbaikan atau tidak. Indikator Traffic Light System ini direpresentasikan dengan tiga warna yaitu hijau, kuning dan merah. Warna hijau merupakan pencapaian dari indikator kinerja sudah tercapai atau bahkan sudah melampaui target.

\section{H. Analytical Hierarchy Process (AHP)}

Metode AHP sangat popular dan digunakan diberbagai struktur permasalahan. AHP memiliki kemampuan untuk memecahkan masalah multiobjektif dan multikriteria didasarkan pada perbandingan preferensi dari setiap elemen hierarki sehingga model pengambilan keputusan yang komprehensif.

Prosedur dalam metode AHP adalah sebagai berikut :

1. Pembentukan hierarki

2. Perbandingan berpasangan

3. Pengecekan konsistensi

4. Evaluasi dari seluruh pembobotan

5. Pengelompokkan keputusan dan penilaian

Pengukuran konsistensi AHP dilakukan dengan tahap mengukur konsistensi setiap matrix matriks perbandingan. Pengukuran didasarkan pada eigenvalue maksimum ( $\lambda$ max $)$.

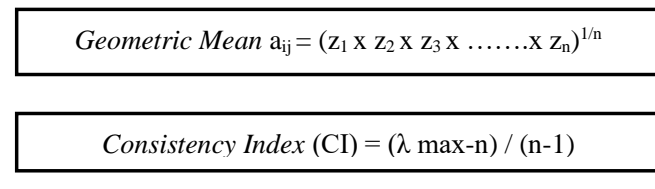

(Pers. 1)

(Pers. 2)

Makin dekat eigenvalue dengan besarnya matriks, makin konsisten matriks tersebut :

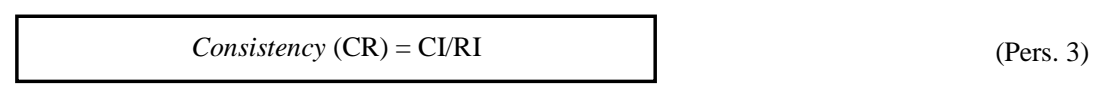


Keterangan :

$\lambda$ max : eigenvalue maksimum

$\mathrm{n} \quad$ : ukuran matriks

RI : random indeks yang diperoleh dari tabel

Batasan diterima tidaknya konsistensi suatu matriks sebenarnya tidak baku. Namun, menurut beberapa eksperimen dan pengalaman, inkonsistensi sebesar $10 \%$ ke bawah tingkat konsistensi yang masih bisa diterima.

\section{RESEARCH METHOD}

Pada tahap ini melakukan pengumpulan data yang berhubungan dengan kegiatan penelitian mengumpulkan data primer dan sekunder. Teknik pengumpulan data dalam penelitian di PT. Pijar Sukma menggunakan Teknik observasi, wawancara dan kuesioner. Setelah melakukan penelitian tentang pengukuran kinerja maka perlu dilakukan analisis dari pengujian hipotesa dan pengolahan data yang telah dilakukan dilangkah-langkah sebelumnya. Dalam penelitian ini terdapat langkah-langkah sebagai berikut:

a. Identifikasi Masalah

Dalam penelitian ini melakukan identifikasi masalah bagaimana pengukuran kinerja yang dilakukan di PT.Pijar Sukma, serta melakukan wawancara secara langsung kepada narasumber untuk mengetahui masalah dengan data yang berkaitan dengan penelitian.

b. Pengumpulan Data

Dalam pengumpulan data menggunakan kuesioner terbuka untuk indetifikasi kepuasan dan kontribusi dari stakeholder. Kuesioner AHP untuk memberikan pembobotan KPI, dan kuesioner penilai KPI untuk menentukan skor aktual.

c. Pengolahan Data

Dalam pengolahan data penelitian ini, Identifikasi Stakeholder adalah orang yang memiliki kepentingan dalam perusahaan seperti : Pemilik usaha, konsumen, supplier, pekerja, dan masyarakat. Identifikasi perspektif dalam performance prism Untuk mengukur kinerja perusahaan dilakukan dengan mengidentifikasi perspektif dalam performance prism, yaitu kepuasaan stakeholder, kontribusi stakeholder, strategi, proses, dan kapabilitas. Menentukan Key Performance Indicator (KPI). Penyusunan Performance Measurement Record Sheet. Objective Matrix (OMAX) dan Traffic Light System yaitu menentukan target nilai yang dicapai KPI dari nilai terendah dan nilai tertinggi, Metode Analytical Hierarchy Process (AHP) untuk menentukan bobot KPI. Menentukan kelas untuk masing-masing KPI dengan meggunakan penilaian KPI yaitu skala likert. Menentukan skor aktual. Menentukan nilai performansi. Pemberian warna sesuai dengan nilai/skor dari indikator.

\section{RESULT AND ANALYSIST}

Data yang dikumpulkan berdasarkan kuesioner terbuka yaitu identifikasi kepuasan dan kontribusi dari stakeholder perusahaan. Kemudian data tersebut dibuat kedalam perspektif bangun prisma yaitu kepuasan, kontribusi, strategi, dan kapbilitas yang akan digunakan sebagai kerangka kerja dan terbentuklah sebuah Key Performance Indicators (KPI). KPI terdiri dari KPI strategi, KPI proses, dan KPI kapabilitas. Berikut merupakan data yang yang telah dibentuk sebagai KPI terdiri:

A. KPI strategi :

1. $\mathrm{S} 1:$ Menambahkan fasilitas kerja

2. S2 : Bahan baku dan peralatan kerja

3. S3 : Harga sesuai kualitas produk

4. S4 : Pelayanan dan fasilitas yang mewadahi

5. S5 : Bahan baku berkualitas dan fungsional

6. S6 : Sistem pelayanan

7. $\mathrm{S} 7$ :Tempat kerja yang nyaman

8. S8 : Pekerjaan sesuai dengan bidang keahlian

9. S9: Kesempatan bekerja dengan perusahaan

10. S10 : Program kerja dengan masyarakat

B. KPI Proses

1. P1 : Mencapai target pasar

2. P2 : Merealisasikan biaya produksi

3. P3 : Proses produksi produk yang sesuai dengan kualitas

4. P4 : Estetika terhadap produk

5. P5 : Harga yang ditawarkan murah dan berkualitas

6. P6 : Penerimaan bahan baku sesuai kebutuhan perusahaan

7. P7 : Aturan jam kerja

8. P8 : Upah kerja sesuai kesepakatan dalam bekerja 
JAST : Journal of Applied Science and Technology

Volume. 02 Number. 01, January 2022

ISSN : 2775-4022

http://jurnal.unissula.ac.id/index.php/JAST

9. P9 : Pemanfaatan limbah

10. P10 : Komunikasi secara baik dengan masyarakat

C. KPI Kapabilitas

1. $\mathrm{K} 1$ : Mengembangkan ide-ide produk dan e-commers

2. $\mathrm{K} 2$ : Meningkatkan kinerja produktivitas

3. K3 : Adanya promosi atas pembelian produk

4. K4 : Kesepakatan antara pembeli dan penjual

5. K5 : Melakukan evaluasi dan pengecekan bahan baku

6. K6 :Adanya kejelasan pemesanan dan transaksi

7. K7 : Tunjangan pekerja

8. K8 : Pelatihan dan pendidikan sumber daya manusia

9. K9 : Pengolahan limbah 3R (Reuse, Reduce, Recycle)

10. K10 : Adanya sosialisasi dan penjadwalan kegiatan

\subsection{Pengolahan Data}

\subsubsection{AHP (Analytical Hierarchy Process)}

Tujuan AHP untukmengetahui tingkat kepentigan dari stakeholder. Berikut merupakan data hasil rekapitulasi perhitungan AHP dengan bantuan MS.Excel.

Tabel 2 Hasil Perhitungan AHP

\begin{tabular}{|c|c|c|c|c|c|}
\hline Nama Kriteria & Bobot Kriteria & Nama Stakeholder & Bobot Antar Stakeholder & KPI & Bobot KPI \\
\hline \multirow{10}{*}{ Strategi } & \multirow{10}{*}{0,387} & \multirow{2}{*}{ Pemilik Usaha } & \multirow{2}{*}{0,420} & S1 & 0,273 \\
\hline & & & & $\mathrm{S} 2$ & 0,053 \\
\hline & & \multirow[b]{2}{*}{ Konsumen } & \multirow[b]{2}{*}{0,110} & S3 & 0,163 \\
\hline & & & & S4 & 0,110 \\
\hline & & \multirow{2}{*}{ Supplier } & \multirow{2}{*}{0,231} & S5 & 0,078 \\
\hline & & & & S6 & 0,077 \\
\hline & & \multirow[t]{2}{*}{ Pekerja } & \multirow[t]{2}{*}{0,061} & S7 & 0,140 \\
\hline & & & & S8 & 0,048 \\
\hline & & \multirow[b]{2}{*}{ Masyarakat } & \multirow{2}{*}{0,178} & S9 & 0,031 \\
\hline & & & & S10 & 0,026 \\
\hline \multirow{10}{*}{ Proses } & \multirow{10}{*}{0,443} & \multirow{2}{*}{ Pemilik Usaha } & \multirow{2}{*}{0,420} & $\mathrm{P} 1$ & 0,152 \\
\hline & & & & $\mathrm{P} 2$ & 0,070 \\
\hline & & \multirow{2}{*}{ Konsumen } & \multirow{2}{*}{0,110} & P3 & 0,155 \\
\hline & & & & $\mathrm{P} 4$ & 0,137 \\
\hline & & \multirow{2}{*}{ Supplier } & \multirow{2}{*}{0,231} & P5 & 0,102 \\
\hline & & & & P6 & 0,073 \\
\hline & & \multirow{2}{*}{ Pekerja } & \multirow[t]{2}{*}{0,061} & $\mathrm{P7}$ & 0,102 \\
\hline & & & & P8 & 0,077 \\
\hline & & \multirow{2}{*}{ Masyarakat } & \multirow{2}{*}{0,178} & P9 & 0,073 \\
\hline & & & & $\mathrm{P} 10$ & 0,060 \\
\hline \multirow{10}{*}{ Kapabilitas } & \multirow{10}{*}{0,169} & \multirow{2}{*}{ Pemilik Usaha } & \multirow{2}{*}{0,420} & $\mathrm{~K} 1$ & 0,101 \\
\hline & & & & K2 & 0,063 \\
\hline & & \multirow{2}{*}{ Konsumen } & \multirow{2}{*}{0,110} & K3 & 0,141 \\
\hline & & & & K4 & 0,138 \\
\hline & & \multirow{2}{*}{ Supplier } & & K5 & 0,108 \\
\hline & & & 0,231 & K6 & 0,071 \\
\hline & & Dolori & 0,061 & K7 & 0,103 \\
\hline & & Pekerja & & K8 & 0,086 \\
\hline & & Masuarakat & 0178 & K9 & 0,088 \\
\hline & & Masyarakat & 0,178 & K10 & 0,102 \\
\hline
\end{tabular}

\subsubsection{Penilaian Key Performance Indicators (KPI)}

Penilaian KPI bertujuan untuk mengukur kinerja aktual dengan menggunakan skala likert dengan skor 1-5. Dari total kuesioner yang tersebar sebanyak 30 responden merupakan orang yang dianggap berkompeten dalam perusahaan. Berikut hasil penilaian KPI :

Tabel 3 Hasil Penilaian Key Performance Indicator (KPI)

\begin{tabular}{rlc}
\hline No. & \multicolumn{1}{c}{ Key Performance Indicators (KPI) } & Nilai KPI \\
\hline 1. & Menambahkan fasilitas kerja (S1) & 3,9 \\
\hline 2. & Bahan baku dan peralatan kerja (S2) & 5 \\
\hline
\end{tabular}


JAST : Journal of Applied Science and Technology

Volume. 02 Number. 01, January 2022

ISSN : 2775-4022

http://jurnal.unissula.ac.id/index.php/JAST

\begin{tabular}{clc}
\hline 3. & Harga sesuai kualitas produk (S3) & 5 \\
\hline 4. & Pelayanan dan fasilitas yang mewadahi (S4) & 5 \\
\hline 5. & Bahan baku berkualitas dan fungsional (S5) & 5 \\
\hline 6. & Sistem pelayanan (S6) & 5 \\
\hline 7. & Tempat kerja yang nyaman (S7) & 1,5 \\
\hline 8. & Pekerjaan sesuai dengan bidang keahlian (S8) & 5 \\
\hline 9. & Kesempatan bekerja dengan perusahaan (S9) & 5 \\
\hline 10. & Program kerja dengan masyarakat (S10) & 2 \\
\hline 11. & Mencapai target pasar (P1) & 5 \\
\hline 12. & Merealisasikan biaya produksi (P2) & 2,5 \\
\hline 13. & Proses produksi produk yang sesuai dengan kualitas (P3) & 4,7 \\
\hline 14. & Estetika terhadap produk (P4) & 5 \\
\hline 15 & Harga yang ditawarkan murah dan berkualitas (P5) & 4,5 \\
\hline 16. & Penerimaan bahan baku sesuai kebutuhan perusahaan (P6) & 1,5 \\
\hline 17. & Aturan jam kerja (P7) & 4 \\
\hline 18. & Upah kerja sesuai kesepakatan dalam bekerja (P8) & 3 \\
\hline 19. & Pemanfaatan limbah (P9) & 3,5 \\
\hline 20. & Komunikasi secara baik dengan masyarakat (P10) & 3,5 \\
\hline 21. & Mengembangkan ide-ide produk dan $e$-commers $(\mathrm{K} 1)$ & 5 \\
\hline 22. & Meningkatkan kinerja produktivitas (K2) & 5 \\
\hline 23. & Adanya promosi atas pembelian produk (K3) & 5 \\
\hline 24. & Kesepakatan antara pembeli dan penjual (K4) & 5 \\
\hline 25. & Melakukan evaluasi dan pengecekan bahan baku (K5) & 4,5 \\
\hline 26. & Adanya kejelasan pemesanan dan transaksi (K6) & 5 \\
\hline 27. & Tunjangan pekerja (K7) & 4 \\
\hline 28. & Pelatihan dan pendidikan sumber daya manusia (K8) & 1 \\
\hline 29. & Pengolahan limbah 3R (Reuse, Reduce, Recycle) (K9) & 5 \\
\hline 30. & Adanya sosialisasi dan penjadwalan kegiatan (K10) & 5 \\
\hline & & \\
\hline & & \\
\hline
\end{tabular}

\subsubsection{Perhitungan Nilai Performansi}

Nilai performansi pada perusahaan $=$ jumlah setiap kriteria $\mathrm{x}$ nilai bobot kriteria

$=(3,099 \times 0,387)+(3,039 \times 0,443)+(1,721 \times 0,169)$

$=1,199+1,273+0,291$

$=2,836$

Tabel 10 Perhitungan Performansi Perusahaan

\begin{tabular}{ccc}
\hline Kriteria & Nilai Performansi kriteria & Nilai bobot kriteria \\
\hline Strategi & 1,199 & 0,387 \\
\hline Proses & 1,273 & 0,442 \\
\hline Kapabilitas & 0,291 & 0,169 \\
\hline Perusahaan & 2,836 & 0,998 \\
\hline
\end{tabular}

\subsection{Analisa}

\subsubsection{Analisa Metode Performance Prism}

Hasil data kuesioner terbuka yang telah dilakukan, didapatkan identifikasi stakeholder dari perusahaan yaitu pemilik usaha, konsumen, supplier, pekerja dan masyarakat. Dengan didapatkan identifikasi stakeholder kemudian dibentuk ke dalam persepktif meliputi kepuasaan, kontribusi, strategi, proses, dan kapabilitas.

\subsubsection{Analisa Pembobotan Key Performance Indicators (KPI) dengan Metode Analytical Hierarchy Process (AHP)}

Hasil perhitungan pembobotan Key Performance Indicators (KPI) menggunakan metode Analytical Hierarchy Process (AHP) Perbandingan antara kriteria dengan nilai bobot dari strategi sebesar 0,387, proses sebesar 0,442, dan kapabilitas sebesar 0,169 dengan hasil nilai rasio inconsistency sebesar sebesar 0,01 lebih kecil $(<0,1)$ dikatakan konsisten. Perbandingan antara stakeholder dengan nilai bobot dari pemilik usaha sebesar 0,420, konsumen sebesar 0,110, supplier sebesar 0,231, pekerja sebesar 0,061, dan masyarakat sebesar 0,1778 dengan hasil nilai rasio inconsistency sebesar 0,04 lebih kecil $(<0,1)$ dikatakan konsisten. Perbandingan pada masingmasing strategi dengan jumlah hasil nilai rasio inconsistency sebesar 0,09 lebih kecil $(<0,1)$ dikatakan konsisten. Perbandingan pada masing-masing proses dengan jumlah hasil nilai rasio inconsistency sebesar 0,08 lebih kecil $(<0,1)$ dikatakan konsisten. Perbandingan pada masing-masing kapabilitas dengan hasil nilai rasio inconsistency sebesar 0,09 lebih kecil $(<0,1)$ dikatakan konsisten. 


\subsubsection{Analisa Nilai Performansi}

Hasil dari perhitungan metode OMAX dan traffic light system dari setiap KPI didapatkan hasil hasil yang perlu melakukan perbaikan kinerja. Pada KPI strategi satu KPI berwarna merah yaitu program kerja dengan masyarakat dengan nilai bobot 0,026 nilai performansi 0,078 nilai aktual 3,00 artinya belum mencapai target yang telah ditetapkan. Pada KPI proses KPI berwarna merah yaitu penerimaan bahan baku sesuai kebutuhan perusahaan dengan nilai bobot 0,073 nilai performansi 0,219 nilai aktual 3,00 artinya belum mencapai target telah ditetapkan. Pada KPI Kapabilitas satu KPI berwarna merah yaitu pelatihan dan pendidikan sumber daya manusia dengan nilai bobot 0,086 nilai performansi 0,086 nilai aktual 2,00 artinya belum mencapai target yang telah ditetapkan.

\section{CONCLUSION}

Berdasarkan pengumpulan dan pengolahan data yang telah diuraikan diatas dapat diuraikan kesimpulan sebagai berikut:

1. Pengukuran kinerja dengan metode performance prism dengan melibatkan stakeholder perusahaan seperti pemilik usaha, konsumen, supplier, pekerja, dan masyarakat. Didapatkan key performance indicators (KPI) yang didasarkan dari identifikasi kepuasaan dan kontribusi kemudian dibentuk dalam strategi, proses, dan kapabilitas. Total KPI yang didapatkan 30 dari 10 kriteria strategi, 10 kriteria proses, dan 10 kriteria kapabilitas.

2. Metode analytical hierarchy proccess (AHP) dan metode OMAX beserta traffic light system didapatkan hasil perhitungan 3 KPI perlu melakukan perbaikan dikarenakan merupakan masih berada didalam kategori warna merah yang artinya belum mencapai maksimal sesuai target dari perusahaan.

3. Usulan perbaikan kinerja sebagai berikut :

a. Program kerja dengan masyarakat pada stakeholder masyarakat yaitu mengadakan sosialisasi kegiatan bersama, mengembangkan lembaga sosial kemasyarakatan maupun keagamaan, dan musyawarah.

b. Penerimaan bahan baku sesuai kebutuhan perusahaan pada stakeholder supplier yaitu adanya kejelasan kesediaan terhadap bahan baku, proses pembuatan bahan baku yang mencukupi persediaan, perkiraan kebutuhan bahan baku, dan waktu pemesanan.

c. Pelatihan dan pendidikan sumber daya manusia pada stakeholder pekerja yaitu melakukan penjadwalan secara teratur dalam pengembangkan sumber daya manusia, memanggil instruktur/guru pelatihan yang berpengalaman, perubahan prosedur dalam sistem perusahaan ,memberikan kesempatan dalam menyalurkan ide atau gagasan sehingga memperoleh kontribusi dan merasa dihargai, dan memberikan penghargaan atas pencapaian prestasi.

4. Nilai indeks performansi perusahaan yaitu sebesar 2,836 dengan bobot 0,998 . Perusaahan berada dalam kategori warna merah dengan nilai aktual sebesar 3,00 artinya perusahaan sudah melakukan pencapaian rencana pengukuran kinerja namun belum mencapai target yang telah ditetapkan sehingga perusahaan dapat mempertahankan kinerja yang baik dan melakukan perubahan kinerja yang buruk.

\section{REFRENCE}

[1.] A.A Anwar Prabu Mangkunegara. (2000). Manajemen Sumber Daya Manusia. PT. Remaja Rosdakarya, Bandung.

[2.] Adianto. (2014). Analisis Pengukuran Kinerja Perusahaan dengan Metode Performance Prism dan Scoring Objective Matrix (OMAX) pada PT. BPAS. Analisis Pengukuran Kinerja Perusahaan Dengan Metode Performance Prism Dan Scoring Objective Matrix (Omax) Pada Pt. Bpas, 18, 61-70.

[3.] Behn, R. D. (2003). Why measure Performance? Different Purposes Require Different Measures.

[4.] Budiarti, I., WP, S. N., \& Budiawan, W. (2019). PENGUKURAN KINERJA PERUSAHAAN DENGAN METODE PERFORMANCE PRISM (Studi Kasus pada PT Bank Rakyat Indonesia (Persero), Tbk. Kantor Cabang .... Industrial Engineering Online ..., 21. https://ejournal3.undip.ac.id/index.php/ieoj/article/view/22518

[5.] Iii Teori, L. (2001). BAB III Landasan Teori 3.1 Analytic Hierarchy Process. 3.1.1 Pengertian Metode Analytic Hierarchy Process (AHP). 12-36.

[6.] Industri, J. T. (2013). Analisis Peningkatan Produktivitas Di Lantai Produksi dengan Menggunakan Metode Objective Matrix (OMAX) * GITA DESTRIANA RAHMI, ABU BAKAR, ARIE DESRIANTY. Jurnal Online Institut Teknologi Nasional Juli, 1(1), 2338-5081.

[7.] Kinanti, W. A., \& Nurhasanah, N. (2019). Usulan Perancangan Key Performance Indicator (KPI) dengan Konsep Green HRM menggunakan Perspektif Performance Prism dan Metode AHP pada Waris Cafe. JURNAL Al-AZHAR INDONESIA SERI SAINS DAN TEKNOLOGI, 5(2), 70. https://doi.org/10.36722/sst.v5i2.353

[8.] Maghfiroh, A dan D, H. (2020). Performance Prism Pada Tenaga Struktural Di Universitas Wahidiyah ( Studi Kasus Di Prodi Ahwalus Syakhsiah ). 2, 1-7.

[9.] Mollah, M. K., \& Erywardana, Y. S. (2019). Analisis Pengukuran Kinerja Dengan Metode Performance Prism Berdasarkan Omax Scoring System di Unit Produksi PDAM Surya Sembada Kota Surabaya. Jurnal Tecnoscienza. 
JAST : Journal of Applied Science and Technology

Volume. 02 Number. 01, January 2022

ISSN : 2775-4022

http://jurnal.unissula.ac.id/index.php/JAST

http://www.ejournal.kahuripan.ac.id/index.php/TECNOSCIENZA/article/view/238

[10.] Mowen, H. \&. (2004). Manajemen Biaya. Jakarta: Salemba Empat.

[11.] Mudrajad, K. (2005). Strategi Bagaimana Meraih Keunggulan Kompetitif. Erlangga. Jakarta.

[12.] Nur, M., \& Yani, D. (2019). Pengukuran Kinerja Perusahaan dengan Menggunakan Integrated Performance $\begin{array}{lllll}\text { Measurement } \quad \text { Systems. } & \text { Industrial }\end{array}$ https://www.journal.unimal.ac.id/miej/article/download/400/295\%0Ahttps://journal.unimal.ac.id/miej/article/view/40 0/295\%0Ahttps://lens.org/118-227-163-145-841

[13.] Purnomo, C. A., \& Hadi, Y. (2017). Pengukuran Kinerja Umkm Menggunakan Performance Prism. Spektrum Industri, 15(2), 121. https://doi.org/10.12928/si.v15i2.7550

[14.] Rufaid, A., \& Vidianto, M. I. (2018). Sistem Pengukuran Kinerja Menggunakan Metode Performance Prism Di Pt Karung Emas Manyar Gresik. Rekayasa, 11(1), 46. https://doi.org/10.21107/rekayasa.v11i1.4124

[15.] Tri Widodo, T., Alamsyah, N., \& Wahyu, Z. (2019). Analisa Pengukuran Kinerja Team Directsselling Pt. Golden Communication Dengan Menggunnakan Metode Balance Scorecard Dan Analytical Hierachy Process (Ahp). Jurnal Industri Kreatif (Jik), 3(1), 89. https://doi.org/10.36352/jik.v3i1.174

[16.] Vanany, I. (2009). Performance Measurement : Model \& Aplikasi. Surabaya: ITSPress. 